\title{
The Research on the Construction of the School-enterprise Cooperation Course of the Network Interconnect Devices in Liberal Education
}

\author{
Dong Kun, Huang Cundong, Fu Xianzheng, Bo Yang \\ Anhui National Defence Vocational Collage \\ Liuan, China \\ e-mail: 443221118@qq.com
}

\begin{abstract}
The paper introduces the construction of the network interconnect device course, which is a school-enterprise cooperation course, in Anhui vocational college of defense technology. In the construction of the course, combining the reality of the computer network technology specialty, the course development teams do some work, focusing on use of the enterprise resource, taking the reality of students into consideration, making the orientation of the course accurately and making the teaching content, method and evaluation reasonably. By persistent reformation in the course, major-building will be based on course-building and w ill be served by course-building, consequently, a sound development system will be established, in which major-building motivates course-building, and course-building promotes major-building. The paper is one part of the quality engineering of Anhui Province, fund number 20101686, and the educating and scientific research project of Anhui National Defence Vocational Collage, fund number 2011gfyy01.
\end{abstract}

Keywords-Vocational education ; course-building; School-enterprise Cooperation; major-building

\section{INTRODUCTION}

Courses-building is an important component of majors-building of higher vocational schools. It requires long term endeavor and needs to continuously adapt itself to the actual teaching situation. It involves many aspects, such as reasonable planning of courses, building of teacher team, accumulation of teaching resources, building of teaching contents, application of teaching methods and examination of teaching quality. Success in courses-building is of great significance for optimization of courses structures, for improvement of teaching effect and for quality assurance of cultivation of application personnel.

The major of computer network technology of Anhui Vocational College of Defense Technology is a provincial special major building site of Anhui Province. Anhui Vocational College of Defense Technology, as an H3C excellent network college, cooperates with H3C Company on building the course of Network Interconnection Equipment. The building of the computer network technology major of our college has been pushed for years, and to keep with the pace of the major-building, the course of Network Interconnection Equipment has also undertaken continuous reformation and innovation.

\section{COURSE OVERVIEW}

\section{A. Course Orientation}

According to the principle of Courses-building Serves Majors-building, this course is oriented to the ability cultivation objectives referred in the personnel cultivation plan of the computer network technology major of Anhui Vocational College of Defense Technology.

Computer Network Technology Major cultivation objectives: cultivation of cultivated skill-oriented professionals, who suit the request of socialism modernization construction, have all-around development in ethics, intelligence, body and arts, suit the request of the front line of production, construction, management and service, have good professional ethics and spirits, master computer network and relevant software, and master construction, management and maintenance of computer network as well as development, management and maintenance of websites.

The cultivation objectives have given a specific objective that making students master construction, management and maintenance of computer network. After analyzing the objective, we divide it into several detailed aspects (see Chart 1, the underlined parts are the contents involved in the course). Most cultivation contents in the chart are involved in the course of Network Interconnection Equipment, so we can see that this course plays an important role in cultivation of computer network technology majored students of Anhui Vocational College of Defense Technology.

Construction,
$\begin{aligned} & \text { management and } \\ & \text { maintenance of } \\ & \text { computer network }\end{aligned}$$\left\{\begin{array}{l}\begin{array}{l}\text { Network } \\ \text { equipment }\end{array} \\ \begin{array}{l}\text { Terminal } \\ \text { equipment }\end{array} \\ \begin{array}{l}\underline{\underline{\text { Network protocol }}} \\ \underline{\text { Switch configuration }} \\ \underline{\text { Vocational standard }} \\ \underline{\text { Terminal PC }}\end{array} \\ \underline{\text { Working practice experience }}\end{array}\right.$

Figure 1. Computer network technology cultivation ability analysis

At the same time, this course acts as a link between the junior basic theoretic courses for cultivation of computer network technology majored students, such as Computer Network Basis and Computer Application Ability, and the senior core courses, such as Network Generic cabling and 
Generic Project Practice. This course takes a key position in the system of courses.

Therefore, according to the position of this course in the cultivation plan and in the system of courses, this course is oriented as a core course of the computer network technology major.

\section{B. Course Ability Objectives and Teaching Objectives}

This course is built on cooperation between college and enterprise. The course objectives and teaching objectives are based on the vocational ability objectives presented by H3C Company, and the actual conditions of our college are also considered. The course ability objectives include four abilities, namely, knowledge ability, practice ability, vocational ability and social ability. The cultivation of these four abilities is interdependent and cannot be separated. See Chart 2, below.

Master solid computer
network basic knowledge
and network
interconnection concept

Figure 2. Course abilities analysis

Knowledge ability is the basis of ability cultivation. Knowledge ability serves practice ability and is the premise of practice ability cultivation. Practice ability serves vocational ability and plays a key role in the vocational ability cultivation. The practice ability cultivation directly influences students' capabilities for vocational positions. Vocational ability is composed of knowledge ability, practice ability and social ability. Vocational ability is the final objective of ability cultivation of this course. Appropriate social ability cultivation aids in forming students' vocational ability and plays an important role in cultivation of students' comprehensive abilities.

\section{Course Designing Concept and Idea}

Knowing the course objectives and the specific teaching objectives, and considering the actual studying conditions of computer network technology majored students of our college, we analyzed the course and fixed the course designing concept and idea.

Course Designing Concept and Idea:

According to the course orientation and teaching objectives, and the actual studying conditions of students, reasonably design the course integrity teaching and course unit teaching(flexible preparation of teaching outline and plan); students first, reasonably and flexibly arrange teaching progress; teach theories as well as practices, flexibly apply teaching methods, such as integrity of Teaching, Studying and Practicing, Project-oriented and Task-motivated, pay attention to cultivation of practical abilities, intensify examinations in classroom, supervise experiment completion effect.

\section{TEACHERS AND TEACHING RESOURCES}

Teachers and various teaching resources are objective guarantee of teaching. Through years of accumulation, the teachers and various resources of this course are sufficient for the building and reformation of this course.

Details of the course teaching staff: at present there are five teachers, including an associate professor, three instructors, and an assistant instructor. Each of the five teachers has H3CNE engineer's qualification, two of them have H3CSE engineer's qualification, two of them have H3CSE instructor's qualification, one of them has H3CNE instructor's qualification.

Network interconnection equipment laboratory: the laboratory is equipped with eight sets of equipment. Each set of equipment is composed of three MSR30-11 routers, two Quidway S3900 third layer switches, one Quidway 1526 second layer switch, four computers, and a multimedia laboratory table for teachers. The laboratory is designed strictly according to the standard and can satisfy the need of experiment or practice teaching.

Textbook: H3C Network College Router and Switch Textbook A and Textbook B. This textbook is written by H3C Company's engineers, for the training of network college H3CNE position engineer, and is published by Tsinghua University Press. This textbook is developed strictly according to vocational standard, the contents are oriented accurately, and the ideas are clear.

Experiment videos, PPT films: experiment videos are available on the teaching equipment, the videos record the process of teaching experiment and aid in teaching. PPT films also aid in teaching.

Website, QQ Group Network Resources: H3C Official Website Forum, and our own QQ group, act as platforms for students to study by themselves and discuss after class.

\section{Course TEACHING Contents Design}

H3C enterprise training and teaching divides the teaching contents into 10 chapters, 47 sections, 41 experiments and one comprehensive practical project of small and medium-sized enterprises network topologic plan. The textbook's contents are rich, the knowledge contents are oriented accurately, and the teaching ideas are clear.

During the development of the course, the course team made the most of $\mathrm{H} 3 \mathrm{C}$ enterprise resources, and designed the actual teaching contents on the basis of H3C enterprise training and teaching contents, the actual conditions of teachers and students were also considered. According to the course teaching objectives and the actual requests of enterprises, referencing the comprehensive practical project contents, considering the actual conditions of our teachers, and the principle of Necessary and Sufficient, we reasonably 
revised the 10 chapters and 47 sections. 35 sections are reserved and 12 sections are deleted. The reserved teaching contents are integrated into a specific project. 19 specific working scenes are designed for the completion process of the project, 1-3 working tasks are designed for each working scene (sub-tasks are designed for each task).

The 19 working scenes are classified according to their application values in the actual work, their completion difficulty and the key knowledge they covered. Some working scenes are paid more attention than others in teaching work.

While specific working tasks are designed for each scene, to standardize the teaching method of Task-motivated, the course team referenced $\mathrm{H} 3 \mathrm{C}$ experiment manual, adopted part of its contents, and developed a standard task manual for each working task. In each task manual, in order to strictly standardize practice teaching, the completion of the experimental task is embodied by the completion of questionaire. For example, Scene 16 IP Router Technology, three tasks and seven sub-tasks are designed for this scene.

Task 1 Principle and configuration of direct or static routing

1. Direct routing and routing table inquiry

2. Static routing configuration

Task 2 Principle and configuration of RIP

1. RIPv1 Configuration

2. RIPv2 Configuration

Task 3 Principle and configuration of OSPF

1. Single area OSPF basic configuration

2. Single area OSPF enhanced configuration

3. Multi area OSPF basic configuration

\section{Course TEAching}

\section{A. Course Teaching Methods}

The course adopts the method of Project-oriented and Task-motivated, cooperates with the industry and enterprise, makes the most of H3C network college's resources, fully considers the actual conditions of students, introduces practical working projects into classrooms, simulates working scenes of vocational positions, integrates classroom and laboratory with enterprise. In the course unit teaching, the interactive teaching method is adopted, let students learn from practice and teachers teach while students practice, teaching, learning and practicing are combined.

First, in the early period of the course teaching, projects are presented, comprehensive project topologic charts are shown to students, actual application conditions are considered, students are guided to analyze the actual functional request. By showing topologic charts and analyzing the request, let students know what the course can do.

Second, in the sector of scene teaching, from the shallow to the deep, according to students' progress, complete the 18 specific scenes set in the project one by one. In the scene teaching, each scene is divided into 1-3 tasks, task-motivated, and examine students' completion of tasks. Meanwhile, after a scene is completed, it will be integrated into the comprehensive project, and then students can know what problem the scene has solved for the comprehensive project.

At last, in the sector of comprehensive project practice, the 18 scenes are reviewed, and through the practical sector, students are asked to independently complete the project topologic plan and deployment.

To assure the teaching quality of the teaching method of Project-oriented and Task-motivated, in each scene unit teaching, the teaching method that teaching, learning and practicing are combined is adopted, the auxiliary teaching methods, such as demonstration, simulation and teaching competition, are also flexibly applied, so the course teaching quality is assured.

The teaching method of Project-oriented and Task-motivated conforms to the rule of students' perception of things, the combination of teaching, learning and practicing assures the teaching quality of each scene, multiple teaching methods are flexibly applied, and good effects are achieved in teaching.

\section{B. Course Examination Methods}

Multiple examination methods are adopted, reformation in examination methods are carried out, and examination methods are made according to students' actual conditions. In the contents of examination, theory are integrated with practice, more attention are paid to examination of practice and innovation ability; according to the characteristic of the course of Network Interconnection Equipment, flexible and various examination methods are made.

In recent years, except the regular examinations, main examination methods that have good application effects in the examination of the course of Network Interconnection Equipment are as follows:

- Competitions are introduced into classrooms, the results of speed competitions in classrooms are counted into the course examination. The competitions arouse students' enthusiasm for studying and raise the teaching efficiency;

- The results of quiz in lectures are included in the course examination and its proportion is increased. The frequency of inspection on completion of teaching tasks in practice lessons is increased, students are urged to study by means of quiz and task reports;

- $\quad$ examines the practice achievement in the sector of comprehensive project;

- Encourage students to join qualification examinations of enterprise and industry, the H3CNE qualification examination results will be counted into the course examination, and such we can promote Double Certificates education.

\section{Teaching Ideas}

In the following phases of course-building, we should further the application of the teaching method Project-oriented and Task-motivated, make the most of cooperation between college and enterprise, target at the request of enterprise, constantly update the contents of 
teaching project, scenes and tasks in the scenes, so we can satisfy the actual needs of enterprise.

Promote the combination of Teaching, Learning and Practicing, intensify lesson management and examination, fulfill the combination of Teaching, Learning and Practicing with examination, realize the combination of Teaching, Learning, Practicing and Examination.

Encourage students to join qualification examinations of enterprise and industry, enhance students' vocational ability; constantly intensify the construction of the course team, encourage the course team to do experiments on the teaching work, promote course-building with teaching scientific research and apply the achievements of the teaching scientific research on the course-building, let the achievements serve the course-building.

\section{CONCLUSION}

The ultimate goal of vocational education is to cultivate professionals that can satisfy the needs of enterprise's positions, while the needs of enterprise change as technical conditions and supply in market change. Therefore, the promotion and reformation of vocational education should adapt themselves to the actual needs of enterprise.

As a core sector of vocational education, course-building also needs to adapt itself to new conditions and situations. During the building process of the course Network Interconnection Equipment, with years of direct participation of enterprise, various resources and advantages of college and enterprise constantly merge, and such make the course Network Interconnection Equipment of Anhui Vocational College of Defense Technology become a professional course that owns reasonable contents and structure, rich teaching resources and a strong force of teachers.

\section{REFERENCES}

[1] Li Dongsheng, On the In-depth Cooperation Model in Engineering Education Between Universities and Enterprise, Research in Higher Education of Engineering, 2011.

[2] Hong Zhenyin, Some Problems and Reflections on School-enterprise In-depth Cooperation in Vocational Education, Journal of Higher Education, 2010.

[3] Liu Fang, Study the Construction of Case Library and the Case Teaching in "Tax Planning" Course Based on the School-enterprise Cooperation Model, Research in Higher Education of Engineering, 2011.

[4] Liu Hequn, Study on Interactive Model of Curriculum Development by School and Enterprise Cooperation in Higher Vocational Schools, Vocational and Technical Education, 2011.

[5] Liu Jianxiang, Construction of School-enterprise Cooperation Course in Vocational Colleges, China Higher Education Research, 2010. 